\title{
Screening for posttraumatic stress disorder in ARDS survivors: validation of the Impact of Event Scale-6 (IES-6)
}

\author{
Megan M. Hosey ${ }^{1,9}$, Jeannie-Marie S. Leoutsakos ${ }^{2}$, Ximin Li ${ }^{3}$, Victor D. Dinglas ${ }^{4,9}$, O. Joseph Bienvenu ${ }^{5,9}$,
} Ann M. Parker ${ }^{4,9}$, Ramona O. Hopkins ${ }^{6,7,8}$, Dale M. Needham ${ }^{1,4,9^{*}}$ and Karin J. Neufeld ${ }^{5,9}$

\begin{abstract}
Background: Posttraumatic stress disorder (PTSD) symptoms are common in acute respiratory distress syndrome (ARDS) survivors. Brief screening instruments are needed for clinical and research purposes. We evaluated internal consistency, external construct, and criterion validity of the Impact of Event Scale-6 (IES-6; 6 items) compared to the original Impact of Event Scale-Revised (IES-R; 22 items) and to the Clinician Administered PTSD Scale (CAPS) reference standard evaluation in ARDS survivors.

Methods: This study is a secondary analysis from two independent multi-site, prospective studies of ARDS survivors. Measures of internal consistency, and external construct and criterion validity were evaluated.

Results: A total of 1001 ARDS survivors (51\% female, 76\% white, mean (SD) age 49 (14) years) were evaluated. The IES-6 demonstrated internal consistency over multiple time points up to 5 years after ARDS (Cronbach's alpha $=0.96$; 95\% confidence interval (CI) 0.94 to 0.97). The IES-6 demonstrated stronger correlations with related constructs (e.g., anxiety and depression; $|r|=0.32$ to 0.52 ) and weaker correlations with unrelated constructs (e.g., physical function and healthcare utilization measures $(|r|=0.02$ to 0.27$)$. Criterion validity evaluation with the CAPS diagnosis of PTSD in a subsample of 60 participants yielded an area under receiver operating characteristic curve $(95 \% \mathrm{Cl})$ of 0.93 $(0.86,1.00)$, with an IES-6 cutoff score of 1.75 yielding 0.88 sensitivity and 0.85 specificity.
\end{abstract}

Conclusions: The IES-6 is reliable and valid for screening for PTSD in ARDS survivors and may be useful in clinical and research settings.

Keywords: Posttraumatic stress disorder, Critical care, Survivorship, Validation studies, Mental health, Psychometric

\section{Background}

Survivors of acute respiratory distress syndrome (ARDS) and other critical illnesses frequently experience symptoms of posttraumatic stress disorder (PTSD) [1-4]. PTSD symptoms are associated with long-lasting impairments in activities of daily living [5] and quality of life $[6,7]$-outcomes of importance to survivors and their families $[8,9]$. Thus, detecting clinically meaningful PTSD symptoms is imperative in this patient population. A valid, reliable and brief screening instrument can assist

\footnotetext{
* Correspondence: Dale.needham@jhmi.edu

'Department of Physical Medicine and Rehabilitation, Johns Hopkins School of Medicine, Baltimore, MD, USA

${ }^{4}$ Division of Pulmonary and Critical Care Medicine, Johns Hopkins School of Medicine, Baltimore, MD, USA

Full list of author information is available at the end of the article
}

in evaluating PTSD symptoms in ARDS survivors in both clinical and research settings.

The Impact of Event Scale-Revised (IES-R) is a 22-item screening instrument, with demonstrated reliability and validity for measuring PTSD symptoms in ARDS survivors [10]. The prior validation study in ARDS survivors compared the IES- $\mathrm{R}$ to the Clinician-Administered PTSD Scale for the DSM-IV (CAPS), a semi-structured clinician interview that serves as a reference standard for PTSD diagnosis. An IES-R score of 1.6 was associated with 100\% sensitivity, $85 \%$ specificity, and $100 \%$ negative and $50 \%$ positive predictive values when compared to the CAP-derived clinical diagnosis of PTSD [10].

An abbreviated 6-item version of the IES-R, known as the IES-6, has demonstrated sensitivity (55-96\%) and

(C) The Author(s). 2019 Open Access This article is distributed under the terms of the Creative Commons Attribution 4.0 International License (http://creativecommons.org/licenses/by/4.0/), which permits unrestricted use, distribution, and 
specificity (74 to 99\%) for PTSD symptoms in evaluations of survivors of trauma, natural disasters, and personal violence in four Norwegian and Welsh samples [11]. The 73\% item reduction from the IES-R to the IES6 decreases completion time and may increase the ease of use and feasibility of administration in clinical practice and research. However, it is unclear if the IES-6 is reliable and valid for detecting PTSD symptoms in ARDS survivors. Hence, the objective of this analysis is to evaluate the internal consistency, criterion validity, and external construct validity of the IES- 6 in ARDS survivors.

\section{Methods}

\section{Participants}

Data used for this analysis were collected as part of two multi-site prospective studies of ARDS survivors: (1) ARDS Network Long-term Outcomes Study (ALTOS) $[12,13]$ and (2) Improving Care of Acute Lung Injury (ALI) Patients (ICAP) [1]. ALTOS enrolled patients from $>40$ hospitals across the USA who participated in four national ARDS Network trials [14-17], with telephone-based follow-up at 6 and 12 months occurring between 2008 and 2014 [12, 13, 18]. The ICAP study evaluated ARDS survivors enrolled from 13 intensive care units (ICUs) at four hospitals in Baltimore, Maryland via in-person follow-up at 3, 6, 12, 24, 36, 48, and 60 months occurring between 2005 and 2012 [1, 19]. The Institutional Review Board of Johns Hopkins University School of Medicine and all participating institutions approved these studies, and patients provided an informed consent.

\section{Measures of PTSD}

The IES- $\mathrm{R}$ is a 22 -item screening instrument assessing PSTD symptoms [20]. Respondents are asked to report how distressed or bothered they are, over the past 7 days, by symptoms related to a specific trauma, using the following scale: "not at all" (item score 0), "a little bit" (score, 1), "moderately" (score, 2), "quite a bit" (score, 3), or "extremely" (score, 4). The IES-6 is an abbreviated 6-item version of the IES-R (Table 1, [11]) with

Table 1 IES-6 questions

\begin{tabular}{ll}
\hline IES-R* item no. & Item \\
\hline 6 & I thought about it when I did not mean to \\
21 & I felt watchful or on-guard \\
3 & Other things kept making me think about it \\
12 & I was aware that I still had a lot of feelings about \\
11 & it, but I didn't deal with them \\
18 & I tried not to think about it \\
\hline
\end{tabular}

*IES-R: Impact of Events Scale-Revised is a 22 item Post-traumatic Stress Disorder (PTSD) screening questionnaire its score calculated as the mean of the six items. The CAPS is a semi-structured interview conducted by a clinician for assessing clinically significant PTSD symptoms and serves as a reference standard for PTSD diagnosis [21].

\section{Measures of external construct validity}

We hypothesized, a priori, that the IES-6 would correlate with other clinically related constructs (i.e., anxiety symptoms and general mental health measures), as evaluated by the following instruments, administered at the same time as the IES-R in ALTOS and ICAP studies: (1) Short Form Health Survey-36 version 2 (SF-36, [22]) Mental Health Domain and Mental Component Summary scores, (2) Hospital Anxiety and Depression Scale (HADS) Anxiety and Depression Symptom Subscales [23], and (3) EQ-5D-3L [24] Anxiety/Depression Item.

In contrast to the prior related constructs, we hypothesized a priori that IES- 6 scores would be more weakly correlated with other clinically unrelated constructs (i.e., physical function and healthcare utilization measures), as evaluated by the following instruments: (1) SF-36 Physical Function (PF) and Role Physical (RF) Domains; (2) EQ-5D-3L Mobility and Self-care items, (3) Functional Performance Inventory-Short Form (FPI-SF) [25] Body Care, Household Maintenance, and Physical Exercise Domains; and (4) healthcare utilization evaluated as ever vs. never using oxygen, x-ray imaging, magnetic resonance imaging, and hemodialysis. All of the aforementioned measures were previously evaluated in ARDS survivors [10, 25-29].

\section{Measure of criterion validity}

Criterion validity of the IES-6 was assessed using the CAPS-based diagnosis of PTSD as previously described.

\section{Study procedures}

In both ALTOS and ICAP studies, trained research staff administered the IES-R at scheduled follow-up assessments [1, 12-14, 19]. Respondents were asked about PTSD symptoms related to their ICU stay for ARDS. The IES-R, SF-36, HADS, EQ-5D-3L, and healthcare utilization survey were asked at follow-up in each of the studies. Only ALTOS participants completed the FPI-SF. As part of a previously reported sub-study [10], 60 of 77 (78\%) participants from ALTOS and ICAP completed a telephone-based CAPS diagnostic interview within 1 week of completing the IES-R. Interviewers included a board-certified attending psychiatrist, a fourth-year psychiatry resident, and a medical student who were extensively trained in the administration of the structured interview. 


\section{Statistical analysis}

The R statistical software package version 3.5.0 was used for statistical analysis. We calculated the correlation between IES-R and IES-6 scores across time points using a longitudinal random effects model with a random intercept. To allow interpretation of the regression coefficient as a correlation, we standardized both IES-R and IES-6 scores using the mean and standard deviation (SD) of scores at 6 months-the earliest time point shared by both datasets. To evaluate internal consistency as a measure of reliability, Cronbach's alpha was calculated for IES-R and IES-6 at each follow-up visit. External construct validity was assessed by examining Pearson correlations (calculated via linear mixed effects) between IES-6 and measures of other constructs, expected to be related or unrelated. We used the same method as described above for correlation between IES- 6 and IES-R, to calculate correlations over time between IES- 6 and measures of these other constructs. We calculated an analogous set of correlations using IES-R to determine if shortening the scale resulted in attenuation of these expected relationships. Finally, criterion validity was assessed by constructing a receiver operating characteristic curve with a diagnosis of PTSD from the CAPS using the pROC R package. The optimal cutoff score for the IES- 6 was obtained, and sensitivity, specificity, negative and positive predictive values were calculated for that cutoff score.

\section{Results}

\section{Demographics and functional outcome measures}

A total of 1001 ARDS survivors (ALTOS: $n=815$; ICAP: $n=186$ ) were included in this evaluation, with $51 \%$ female, 76\% white, and a mean (SD) age of 49 (14) years (Table 2). Mean values for the IES-R and IES-6 instruments are reported at each of the follow-up assessments in Table 3. In addition, mean scores for measures of constructs expected to be either related or unrelated with PTSD were derived from all follow-up visits (Table 3).

\section{IES-R/IES-6 correlations and internal consistency}

The correlation $(95 \% \mathrm{CI})$ of the IES-R and the IES- 6 was 0.96 (0.94 to 0.97) overall assessments. Internal consistency for the IES-6 was good to excellent over time (Cronbach's alpha of 0.86 to 0.91 ; Table 4).

\section{External construct validity}

The IES- 6 was moderately correlated with related measures of mental health constructs, including SF-36 Mental Health Domain and Mental Component Summary $(|\mathrm{r}|, 0.42$; $95 \% \mathrm{CI}, 0.39$ to 0.46 ; and 0.46 ; $95 \% \mathrm{CI}, 0.42$ to 0.49 respectively), the HADS Anxiety Subscale (|r|, 0.52; 95\% CI, 0.49 to 0.55), the HADS Depression Subscale $(|r|, 0.40 ; 95 \% \mathrm{CI}, 0.37$ to 0.44$)$ and the EQ-5D-3L
Table 2 Baseline characteristics of ARDS survivors from two multicenter cohort studies

\begin{tabular}{|c|c|c|}
\hline Characteristic & $\begin{array}{l}\text { ALTOS }^{a} \\
n=815\end{array}$ & $\begin{array}{l}\text { ICAP }^{b} \\
n=186\end{array}$ \\
\hline Male, n (\%) & $389(48)$ & $105(56)$ \\
\hline \multicolumn{3}{|l|}{ Race, $n$ (\%) } \\
\hline White & $655(80)$ & 107 (58) \\
\hline Black & $121(15)$ & $75(40)$ \\
\hline Other & $39(5)$ & $4(2)$ \\
\hline Age mean $(S D)^{c}$ & $49.5(14.7)$ & $49.1(14.1)$ \\
\hline Body mass index mean (SD) & $30.8(8.7)$ & $28.2(7.2)$ \\
\hline APACHE $\|$ mean $(S D)^{d}$ & $26.0(8.4)$ & $23.8(8.1)$ \\
\hline ICU length of stay median $(\mathrm{IQR})^{\mathrm{e}}$ & $10(7,16)$ & $14(10,23)$ \\
\hline Hospital length of stay mean (IQR) & $17(12,26)$ & $26(16,36)$ \\
\hline \multicolumn{3}{|c|}{ Sample size at follow-up assessment ${ }^{f}(n)$} \\
\hline 3 months & $\mathrm{n} / \mathrm{a}$ & 186 \\
\hline 6 months & 804 & 186 \\
\hline 12 months & 797 & 178 \\
\hline 24 months & $\mathrm{n} / \mathrm{a}$ & 163 \\
\hline 36 months & $\mathrm{n} / \mathrm{a}$ & 145 \\
\hline 48 months & $\mathrm{n} / \mathrm{a}$ & 138 \\
\hline 60 months & $\mathrm{n} / \mathrm{a}$ & 137 \\
\hline CAPS $^{9}$ & 35 & 25 \\
\hline
\end{tabular}

${ }^{a}$ ALTOS: Acute Respiratory Distress Syndrome (ARDS) Network Long-term

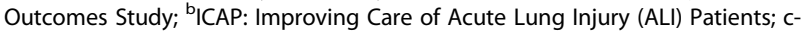
Mean (standard deviation); d-APACHE II-Acute Physiology and Chronic Health Evaluation; ${ }^{\mathrm{e}}$ Median (Interquartile Range); ${ }^{\mathrm{f}} \mathrm{ALTOS}$ evaluated patients at 6- and 12-month time points only; the decrease in sample size over time for both ALTOS and ICAP studies was due to ongoing patient mortality along with loss to follow-up; g-CAPS: Clinician Administered PTSD Scale: 35 ALTOS patients with follow-up at 1 year and 25 ICAP patients followed up at 2, 3, 4, or 5 years

Anxiety/Depression Item (|r|, 0.32; 95\% CI, 0.28 to 0.35 ). The IES-R 22-item version demonstrated the same pattern of associations with these measures, in both magnitude and direction (Table 5).

When compared to correlations with related constructs (above), the IES-6 demonstrated weaker correlations with constructs hypothesized to be unrelated to mental health (Table 5). Of these measures, healthcare utilization variables were least related to the IES- 6 ranging from the utilization of MRI (|r|, 0.02; 95\% CI 0.02 to 0.07$)$ to utilization of Xrays $(|\mathrm{r}|, 0.05$; $95 \% \mathrm{CI} 0.01$ to 0.10$)$. The IES- 6 also had a weak correlation with the EQ-5D-3L Mobility and Self Care items (|r|, 0.15; 95\% CI, 0.11 to 0.19 ; and $|\mathrm{r}|, 0.12$; $95 \% \mathrm{CI}$, 0.09 to 0.16 , respectively), the SF-36 Role Physical and Physical Function Domains (|r|, 0.27; 95\% CI, 0.24 to 0.32; and $|\mathrm{r}|, 0.21 ; 95 \% \mathrm{CI}, 0.18$ to 0.24 , respectively), and the FPI Body Care, Maintain Household, and Physical Exercise domains (|r|, 0.22; 95\% CI, 0.18 to $0.27 ;|\mathrm{r}|, 0.26$; $95 \% \mathrm{CI}, 0.21$ to $0.30 ;|\mathrm{r}|, 0.24 ; 95 \% \mathrm{CI}, 0.20$ to 0.29 , respectively). Again, these patterns of correlations were similar in magnitude and direction for the IES-R 22 item version (Table 5). 
Table 3 Outcome measures in ARDS survivors from two multicenter cohort studies

\begin{tabular}{|c|c|c|}
\hline Outcome measure & $\begin{array}{l}\text { ALTOS }^{a} \\
n=815\end{array}$ & $\begin{array}{l}\text { ICAP }^{\text {b }} \\
n=186\end{array}$ \\
\hline \multicolumn{3}{|l|}{ IES-R ${ }^{d}$ at follow-up mean $(S D)^{c}$} \\
\hline 3 months & $\mathrm{n} / \mathrm{a}$ & $1.1(0.9)$ \\
\hline 6 months & $1.0(0.9)$ & $0.9(0.8)$ \\
\hline 12 months & $1.0(0.9)$ & $0.9(0.9)$ \\
\hline 24 months & $\mathrm{n} / \mathrm{a}$ & $0.9(0.9)$ \\
\hline 36 months & $\mathrm{n} / \mathrm{a}$ & $0.8(0.8)$ \\
\hline 48 months & $\mathrm{n} / \mathrm{a}$ & $0.7(0.9)$ \\
\hline 60 months & $\mathrm{n} / \mathrm{a}$ & $0.7(0.9)$ \\
\hline Across all time points & $1(0.9)$ & $0.9(0.9)$ \\
\hline \multicolumn{3}{|l|}{ IES-6e at follow-up mean (SD) } \\
\hline 3 months & $\mathrm{n} / \mathrm{a}$ & $1.1(0.9)$ \\
\hline 6 months & $1.1(1.0)$ & $0.9(0.9)$ \\
\hline 12 months & $1.0(1.1)$ & $0.9(0.9)$ \\
\hline 24 months & $\mathrm{n} / \mathrm{a}$ & $0.9(0.9)$ \\
\hline 36 months & $\mathrm{n} / \mathrm{a}$ & $0.8(0.9)$ \\
\hline 48 months & $\mathrm{n} / \mathrm{a}$ & $0.7(0.9)$ \\
\hline 60 months & $\mathrm{n} / \mathrm{a}$ & $0.7(0.9)$ \\
\hline Across all time points & $1.1(1.0)$ & $0.8(0.9)$ \\
\hline \multicolumn{3}{|c|}{ External construct validity (related) mean $(S D)^{f}$} \\
\hline SF-36 ${ }^{9}$ Mental Health Domain & $44.5(14.3)$ & $47.1(13.1)$ \\
\hline SF-36 ${ }^{9}$ Mental Component Summary & $45.3(14.86)$ & $47.2(13.2)$ \\
\hline HADS $^{\text {h }}$ Anxiety & $7.0(5.1)$ & $5.9(4.7)$ \\
\hline HADS ${ }^{h}$ Depression & $6.0(4.9)$ & $5.1(4.3)$ \\
\hline EQ-5D-3L Anxiety/Depression Item & $1.7(0.7)$ & $1.6(0.6)$ \\
\hline \multicolumn{3}{|c|}{ External construct validity (unrelated) mean (SD) } \\
\hline SF-36 $6^{9}$ Role Physical Subscale & $38.5(13.0)$ & $39.6(12.8)$ \\
\hline SF-369 Physical Function Subscale & $37.0(13.4)$ & $38.3(13.0)$ \\
\hline EQ-5D-3L Mobility Item & $1.6(0.5)$ & $0.6(0.5)$ \\
\hline EQ-5D-3L Self-Care Item & $1.3(0.5)$ & $0.2(0.5)$ \\
\hline FPI' Body Care domain & $2.6(0.6)$ & $\mathrm{n} / \mathrm{a}$ \\
\hline FPI' Maintain Household & $1.9(0.9)$ & $\mathrm{n} / \mathrm{a}$ \\
\hline FPI' Physical Exercise & $1.6(0.9)$ & $\mathrm{n} / \mathrm{a}$ \\
\hline \multicolumn{3}{|l|}{ Healthcare utilization, $\%$ of patients utilizing } \\
\hline Oxygen therapy & 18.4 & 14.9 \\
\hline X-ray & 53.1 & 52.3 \\
\hline $\mathrm{MRI}^{j}$ & 21.6 & 28.9 \\
\hline$C T^{\mathrm{k}}$ & 27.7 & 34.0 \\
\hline
\end{tabular}

${ }^{\mathrm{a}}$ ALTOS Acute Respiratory Distress Syndrome (ARDS) Network Long-term Outcomes Study (evaluated patients at 6- and 12-month time points); ${ }^{\mathrm{b}}$ ICAP Improving Care of Acute Lung Injury (ALI) Patients; ${ }^{C}$ Mean (standard deviation);

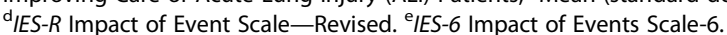
${ }^{f}$ Construct validity measures include mean values (SD) from visits at all available follow-up time points. ${ }^{9}$ SF-36 Short Form Healthy Survey-36 Version 2. ${ }^{\mathrm{h}}$ HADS Hospital Anxiety and Depression Scale; ${ }^{\mathrm{i}} \mathrm{FPI}$ Functional Performance Inventory collected for ALTOS only; ${ }^{\mathrm{j}} \mathrm{MRI}$ magnetic resonance imaging; ${ }^{\mathrm{k}} \mathrm{CT}$ computed tomography
Table 4 Internal consistency: Cronbach's alpha statistic for the IES-R and IES-6

\begin{tabular}{lll}
\hline Follow-up visit & IES- $^{*}$ & IES-6** \\
\hline 3 months & 0.94 & 0.86 \\
6 months & 0.95 & 0.86 \\
12 months & 0.96 & 0.90 \\
24 months & 0.95 & 0.85 \\
36 months & 0.95 & 0.86 \\
48 months & 0.96 & 0.91 \\
60 months & 0.96 & 0.89 \\
\hline
\end{tabular}

*IES-R: Impact of Events Scale—Revised; **|ES-6: Impact of Events Scale-6

\section{Criterion validity of the IES- 6}

Comparison of the IES- 6 to the clinician-based current CAP diagnosis of PTSD (13\% with PTSD at time of interview and $28 \%$ ever experiencing PTSD post-ARDS) yielded an AUROC of 0.93 (95\% CI, 0.86 to 1.00) (Fig. 1). The optimal cut-off point is 1.75 , resulting in a sensitivity of 0.88 , specificity of 0.85 and positive and negative predictive values of 0.47 and 0.98 respectively.

\section{Discussion}

In this evaluation of 1001 ARDS survivors from two multi-site prospective longitudinal studies, the abbreviated IES-6 PTSD screening instrument had good internal consistency with very strong correlations over time with the original 22-item IES-R instrument. External construct validity of the IES- 6 was demonstrated by stronger correlations with measures of related constructs (i.e., mental health, anxiety, and depression) over time, and weaker correlations with measures of unrelated constructs (i.e., physical function and healthcare utilization). The IES-6 demonstrated good criterion validity with a cut point of 1.75 resulted in a sensitivity of 0.88 and a specificity of 0.85 when compared to a reference-standard PTSD semi-structured diagnostic clinician interview.

When compared to the PTSD reference standard, the sensitivity and specificity of the IES-6 is slightly lower than the original 22-item IES-R [10], reported as sensitivity $=1.00$, specificity $=0.85$. However, classification rates remain high with the IES-6, particularly in view of the brevity of the instrument. Use of the IES- 6 compared to the IES- $\mathrm{R}$ is expected to result in a $75 \%(4.5$ min) reduction in administration time. This important time savings increases the feasibility of PTSD screening for both clinical and research purposes. To our knowledge, the IES-6 is the briefest measure of PTSD symptoms validated in ARDS or ICU survivors, even shorter than the Posttraumatic Stress Syndrome 10-Questions Inventory (PTSS-10), which also has been used in ARDS survivors [30]. More research is needed to compare the reliability and validity of the IES- 6 against the PTSS-10. 
Table 5 External construct validity (related and unrelated measures) for IES-R and IES-6

\begin{tabular}{|c|c|c|}
\hline & IES-R & IES-6 \\
\hline & $r(95 \% \mathrm{Cl})^{*}$ & $r(95 \% \mathrm{Cl})^{*}$ \\
\hline \multicolumn{3}{|l|}{ Related measures } \\
\hline SF-36 Mental Health Domain & $-0.45(-0.48,-0.42)$ & $-0.42(-0.46,-0.39)$ \\
\hline SF-36 Mental Component Summary & $-0.48(-0.52,-0.45)$ & $-0.46(-0.49,-0.42)$ \\
\hline EQ-5D-3L-Anxiety/Depression item & $0.33(0.29,0.37)$ & $0.32(0.28,0.35)$ \\
\hline HADS_Anxiety Subscale & $0.55(0.52,0.58)$ & $0.52(0.49,0.55)$ \\
\hline HADS_Depression Subscale & $0.42(0.39,0.46)$ & $0.40(0.37,0.44)$ \\
\hline \multicolumn{3}{|l|}{ Unrelated measures } \\
\hline SF-36 Role Physical Domain & $-0.30(-0.34,-0.26)$ & $-0.27(-0.32,-0.24)$ \\
\hline SF-36 Physical Function Domain & $-0.23(-0.26,-0.19)$ & $-0.21(-0.24,-0.18)$ \\
\hline EQ-5D-3L Mobility & $0.16(0.12,0.20)$ & $0.15(0.11,0.19)$ \\
\hline EQ-5D-3L Self-Care & $0.12(0.09,0.16)$ & $0.12(0.09,0.16)$ \\
\hline $\mathrm{FPI}^{\mathrm{c}}$ Body Care & $-0.26(-0.30,-0.21)$ & $-0.22(-0.27,-0.18)$ \\
\hline FPI Maintain Household & $-0.28(-0.33,-0.24)$ & $-0.26(-0.30,-0.21)$ \\
\hline FPI Physical Exercise & $-0.28(-0.32,-0.23)$ & $-0.24(-0.29,-0.20)$ \\
\hline \multicolumn{3}{|l|}{ Healthcare Utilization } \\
\hline Oxygen Therapy & $0.05(0.00,0.09)$ & $0.04(0.00,0.08)$ \\
\hline X-ray & $0.07(0.02,0.12)$ & $0.05(0.01,0.10)$ \\
\hline MRI & $0.03(-0.02,0.08)$ & $0.02(-0.02,0.07)$ \\
\hline CT & $0.04(0.01,0.08)$ & $0.03(0.02,0.07)$ \\
\hline
\end{tabular}

${ }^{*} r=$ correlation coefficient computed with longitudinal random effects model. 95\% Cl 95\% confidence interval. SF-36 Short Form Healthy Survey-36 Version 2, HADS Hospital Anxiety and Depression Scale, FPI Functional Performance Inventory collected during ALTOS only, MRI magnetic resonance imaging, CT computed tomography

A scoping review of outcome measurement in studies of critical illness survivors reported substantial heterogeneity, including in the evaluation of PTSD symptoms [31]. Such heterogeneity results in a reduced ability to compare and synthesize existing evidence in order to advance the field [31]. Agreement regarding the measurement of PTSD symptoms is especially important given that an international consensus process identified PTSD as an important outcome domain to be included in all clinical research studies evaluating post-discharge outcomes for acute respiratory failure and ARDS (ARF/ ARDS) survivors [32]. This same consensus process specifically recommended the IES-R measure for evaluating PTSD symptoms as part of a minimum core outcomes measurement set (COMS) for ARF/ARDS survivorship research [9]. Our current analysis suggests the abbreviated IES-6, rather than the original IES-R, could improve efficiency, while maintaining adequate measurement properties in screening for PTSD symptoms $[9,32]$. Further replication of these findings in other ARDS/ARF populations would be valuable.

Screening for PTSD symptoms may be assisted by knowledge of established risk factors. Studies have consistently demonstrated that light (vs. deep) sedation, severity of illness, and ICU length of stay are not associated with post-discharge symptoms of PTSD in survivors of critical illness $[1,2,4,33,34]$. However, common risk factors in this patient population include pre-existing psychiatric comorbidity (e.g., anxiety, depression, and substance misuse), benzodiazepine use in the ICU, and memories of frightening ICU experiences after discharge $[1,2,4,33$, 35]. Consideration of these issues, along with IES-6 screening, may assist with risk stratification of patients for PTSD symptoms after hospital discharge.

Strengths of this study include its large sample size, with follow up at multiple time points up to 5 years after ARDS onset. Moreover, to our knowledge, this is the first study of the IES-6 in ARDS survivors. However, this evaluation does have some potential limitations. First, the number of participants in the sub-study using the CAPS reference standard was small. However, the confidence interval for the $\operatorname{AUC}[0.93(0.86,1.0)]$ is relatively precise and suggests this finding is robust. Second, to investigate overlapping variance and test-retest reliability, it is recommended that the original IES-R and abbreviated 6-item version being administered separately at multiple time points [36]. Independent replication is required to address this point. Third, the abbreviated measure reduces the ability to assess PTSD symptom clusters (i.e., avoidance, hyperarousal, intrusion), although the IES-6 does retain 2 items from 


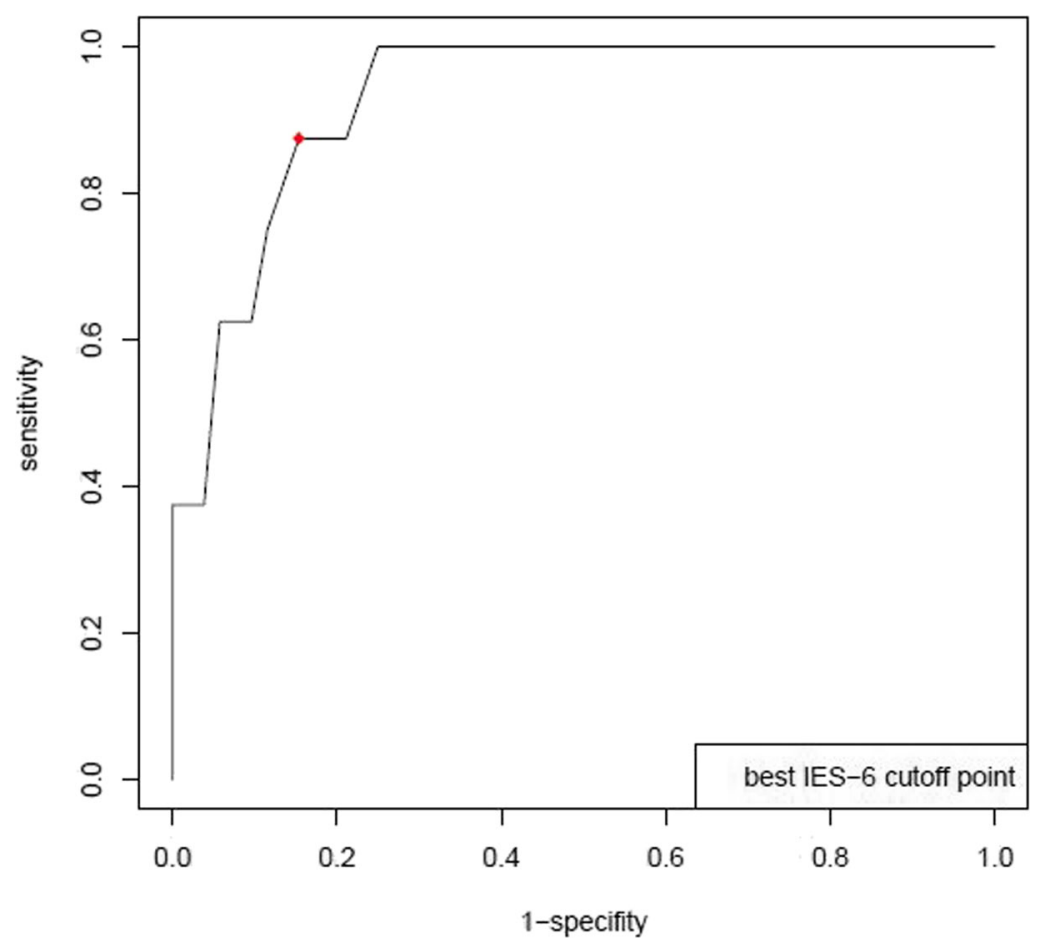

Fig. 1 Receiver operating curve for IES-6 versus CAPS for DSM-IV Diagnosis of PTSD (posttraumatic stress disorder); area under the curve (95\% confidence interval $)=0.93(0.86,1.00)$; Based on $n=60$ (13\% with PTSD at time of interview, $26 \%$ ever experiencing PTSD post-ARDS). Optimal cut-off score for IES-6 is 1.75

each cluster [36]. However, the IES-6 can serve as a valid screening tool using a binary cut-off for clinically important PTSD symptoms. Finally, the generalizability of this study is limited given that only ARDS survivors from the United States were evaluated. Further studies of other critical illness survivors in other locations are warranted.

\section{Conclusion}

Based on an evaluation of 1001 ARDS survivors, from two independent multi-site prospective studies longitudinally evaluating patients for up to 5 years, we conclude that the IES-6 is a reliable and valid screening tool for detecting clinically significant symptoms of PTSD. This very brief IES-6 instrument may be of value for PTSD screening during both clinical and research follow-up evaluations.

\section{Abbreviations}

ALI: Acute Lung Injury; ALTOS: ARDS Network Long-term Outcomes Study; ARDS: Acute Respiratory Distress Syndrome; CAPS: Clinician-Administered PTSD Scale; FPI-SF: Functional Performance Inventory-Short Form; HADS: Hospital Anxiety and Depression Scale; ICAP: Improving Care of ALI Patients; ICU: Intensive care unit; IES-6: Impact of Event Scale-6; IES-R: Impact of Event Scale-Revised; PTSD: Posttraumatic stress disorder; SF-36: Short Form-36 version 2

\section{Authors' contributions}

All authors contributed to the conception and/or design of this study. DMN, VDD, and OJB contributed to the acquisition of data. JML and XL contributed to the analysis of data, and all authors contributed to the interpretation of data. $\mathrm{MMH}$ and $\mathrm{KJN}$ drafted the manuscript, and all authors critically revised it for important intellectual content and approved the final version to be submitted.

\section{Funding}

This research was supported by the NHLBI (R24 HL111895, R01HL091760, R01HL091760-02S1, R01HL088045, and P50HL073944), the Johns Hopkins Institute for Clinical and Translational Research (ICTR) (UL1 TR 000424-06), and the ARDS Network ALTA, EDEN, OMEGA, and SAILS trials (contracts HHSN268200536165C to HHSN268200536176C and HHSN268200536179C).

Availability of data and materials

Not applicable.

Ethics approval and consent to participate

The Institutional Review Board of Johns Hopkins University School of Medicine and all participating institutions approved these studies, and patients provided informed consent.

\section{Consent for publication}

Not applicable. Our study contains no individual data.

\section{Competing interests}

The authors declare that they have no competing interests.

\section{Author details}

${ }^{1}$ Department of Physical Medicine and Rehabilitation, Johns Hopkins School of Medicine, Baltimore, MD, USA. ${ }^{2}$ Department of Psychiatry and Behavioral Sciences, Johns Hopkins School of Medicine, Baltimore, MD, USA.

${ }^{3}$ Department of Biostatistics, Johns Hopkins Bloomberg School of Public Health, Baltimore, MD, USA. ${ }^{4}$ Division of Pulmonary and Critical Care Medicine, Johns Hopkins School of Medicine, Baltimore, MD, USA.

${ }^{5}$ Department of Psychiatry and Behavioral Sciences, Johns Hopkins School of Medicine, Baltimore, MD, USA. ${ }^{6}$ Department of Medicine, Pulmonary and

Critical Care Division, Intermountain Medical Center, Murray, UT, USA. ${ }^{7}$ Center 
for Humanizing Critical Care, Intermountain Health Care, Murray, UT, USA. ${ }^{8}$ Neuroscience Center and Psychology Department, Psychology Department and Neuroscience Center, Brigham Young University, Provo, UT, USA. ${ }^{9}$ Outcomes After Critical Illness and Surgery (OACIS) Group, Johns Hopkins School of Medicine Baltimore, MD, USA.

Received: 18 April 2019 Accepted: 23 July 2019

Published online: 07 August 2019

\section{References}

1. Bienvenu OJ, Friedman LA, Colantuoni E, Dinglas VD, Sepulveda KA, Mendez-Tellez $P$, et al. Psychiatric symptoms after acute respiratory distress syndrome: a 5-year longitudinal study. Intensive Care Med. 2018;44:38-47.

2. Jackson JC, Jutte JE, Hunter $\mathrm{CH}$, Ciccolella N, Warrington $\mathrm{H}$, Sevin $\mathrm{C}$, et al. Posttraumatic stress disorder (PTSD) after critical illness: a conceptual review of distinct clinical issues and their implications. Rehabil Psychol. 2016;61:132.

3. Bienvenu OJ, Gellar J, Althouse BM, Colantuoni E, Sricharoenchai T, MendezTellez PA, et al. Post-traumatic stress disorder symptoms after acute lung injury: a 2-year prospective longitudinal study. Psychol Med. 2013;43:2657-71.

4. Parker AM, Sricharoenchai T, Raparla S, Schneck KW, Bienvenu OJ, Needham DM. Posttraumatic stress disorder in critical illness survivors: a metaanalysis. Crit Care Med. 2015:43:1121-9.

5. Jackson JC, Pandharipande PP, Girard TD, Brummel NE, Thompson JL, Hughes CG, et al. Depression, post-traumatic stress disorder, and functional disability in survivors of critical illness in the BRAIN-ICU study: a longitudinal cohort study. Lancet RespirMed. 2014:2:369-79.

6. Kapfhammer HP, Rothenhausler HB, Krauseneck T, Stoll C, Schelling G. Posttraumatic stress disorder and health-related quality of life in longterm survivors of acute respiratory distress syndrome. AmJ Psychiatry. 2004:161:45-52.

7. Davydow DS, Desai SV, Needham DM, Bienvenu OJ. Psychiatric morbidity in survivors of the acute respiratory distress syndrome: a systematic review. Psychosom Med. 2008;70:512-9.

8. Dinglas VD, Faraone LN, Needham DM. Understanding patient-important outcomes after critical illness: a synthesis of recent qualitative, empirical, and consensus-related studies. Curr Opin Crit Care. 2018;24:401-9.

9. Needham DM, Sepulveda KA, Dinglas VD, Chessare CM, Friedman LA, Bingham CO III, et al. Core outcome measures for clinical research in acute respiratory failure survivors. An international modified Delphi consensus study. Am J Respir Crit Care Med. 2017;196:1122-30.

10. Bienvenu OJ, Williams JB, Yang A, Hopkins RO, Needham DM. Posttraumatic stress disorder in survivors of acute lung injury evaluating the Impact of Event Scale-Revised. Chest. 2013;144:24-31.

11. Thoresen S, Tambs K, Hussain A, Heir T, Johansen VA, Bisson Jl. Brief measure of posttraumatic stress reactions: Impact of Event Scale-6. Soc Psychiatry Psychiatr Epidemiol. 2010;45:405-12.

12. Needham DM, Dinglas VD, Bienvenu OJ, Colantuoni E, Wozniak AW, Rice TW, et al. One year outcomes in patients with acute lung injury randomised to initial trophic or full enteral feeding: prospective follow-up of EDEN randomised trial. BMJ. 2013;346:f1532.

13. Dinglas VD, Hopkins RO, Wozniak AW, Hough CL, Morris PE, Jackson JC, et al. One-year outcomes of rosuvastatin versus placebo in sepsis-associated acute respiratory distress syndrome: prospective follow-up of SAlLS randomised trial. Thorax. 2016;71:401-10.

14. Matthay MA, Brower RG, Carson S, Douglas IS, Eisner M, Hite D, et al. Randomized, placebo-controlled clinical trial of an aerosolized beta (2)agonist for treatment of acute lung injury. Am J Respir Crit Care Med. 2011; 184:561-8.

15. Rice TW, Wheeler AP, Thompson BT, de Boisblanc BP, Steingrub J, Rock P. Enteral omega-3 fatty acid, gamma-linolenic acid, and antioxidant supplementation in acute lung injury. JAMA. 2011;306:1574-81.

16. Rice TW, Wheeler AP, Thompson BT, Steingrub J, Hite RD, Moss M, et al. Initial trophic vs full enteral feeding in patients with acute lung injury: the EDEN randomized trial. JAMA. 2012;307:795-803.

17. Truwit JD, Bernard GR, Steingrub J, Matthay MA, Liu KD, Albertson TE, et al. Rosuvastatin for sepsis-associated acute respiratory distress syndrome. N Engl J Med. 2014;370:2191-200.

18. Needham DM, Colantuoni E, Dinglas VD, Hough CL, Wozniak AW, Jackson $\mathrm{JC}$, et al. Rosuvastatin versus placebo for delirium in intensive care and subsequent cognitive impairment in patients with sepsis-associated acute respiratory distress syndrome: an ancillary study to a randomised controlled trial. Lancet Respir Med. 2016;4:203-12.

19. Bienvenu OJ, Colantuoni E, Mendez-Tellez PA, Shanholtz C, DennisonHimmelfarb CR, Pronovost PJ, et al. Cooccurrence of and remission from general anxiety, depression, and posttraumatic stress disorder symptoms after acute lung injury: a 2-year longitudinal study. Crit Care Med. 2015;43: 642-53.

20. Weiss DS. The impact of event scale - revised. In: Wilson JP, Keane TM, editors. Assessing psychological trauma and PTSD: a practitioner's handbook. New York: Guilford Press; 2004. p. 168-89.

21. Blake DD, Weathers FW, Nagy LM, Kaloupek DG, Gusman FD, Charney DS, et al. The development of a Clinician-Administered PTSD Scale. J Trauma Stress. 1995;8:75-90.

22. Hawthorne G, Osborne RH, Taylor A, Sansoni J. The SF36 version 2: critical analyses of population weights, scoring algorithms and population norms, Qual Life Res. 2007;16:661-73.

23. Zigmond AS, Snaith RP. The hospital anxiety and depression scale. Acta Psychiatr Scand. 1983;67:361-70.

24. EuroQol Group. EuroQol--a new facility for the measurement of healthrelated quality of life. Health Policy Amst Neth. 1990;16:199-208.

25. Leidy NK. Psychometric properties of the functional performance inventory in patients with chronic obstructive pulmonary disease. Nurs Res. 1999;48: 20-8.

26. Pfoh ER, Chan KS, Dinglas VD, Cuthbertson BH, Elliott D, Porter R, et al. The SF-36 offers a strong measure of mental health symptoms in survivors of acute respiratory failure. A tri-national analysis. Ann Am Thorac Soc. 2016;13: 1343-50.

27. Badia X, Diaz-Prieto A, Gorriz MT, Herdman M, Torrado H, Farrero E, et al. Using the EuroQol-5D to measure changes in quality of life 12 months after discharge from an intensive care unit. Intensive Care Med. 2001;27:1901-7.

28. Jutte JE, Needham DM, Pfoh ER, Bienvenu OJ. Psychometric evaluation of the Hospital Anxiety and Depression Scale 3 months after acute lung injury. J Crit Care. 2015:30:793-8.

29. Ruhl AP, Huang M, Colantuoni E, Lord RK, Dinglas VD, Chong A, et al. Healthcare resource use and costs in long-term survivors of acute respiratory distress syndrome: a 5-year longitudinal cohort study. Crit Care Med. 2017:45:196-204.

30. Stoll C, Kapfhammer HP, Rothenhausler HB, Haller M, Briegel J, Schmidt M, et al. Sensitivity and specificity of a screening test to document traumatic experiences and to diagnose post-traumatic stress disorder in ARDS patients after intensive care treatment. Intensive Care Med. 1999;25:697-704.

31. Turnbull AE, Rabiee A, Davis WE, Nasser MF, Venna VR, Lolitha R, et al. Outcome measurement in ICU survivorship research from 1970 to 2013: a scoping review of 425 publications. Crit Care Med. 2016;44:1267-77.

32. Turnbull AE, Sepulveda KA, Dinglas VD, Chessare CM, Bingham CO, Needham DM. Core domains for clinical research in acute respiratory failure survivors: an international modified Delphi consensus study. Crit Care Med. 2017:45:1001-10.

33. Huang M, Parker AM, Bienvenu OJ, Dinglas VD, Colantuoni E, Hopkins RO, et al. Psychiatric symptoms in acute respiratory distress syndrome survivors: a one-year national multi-center study. Crit Care Med. 2016;44:954-65.

34. Devlin JW, Skrobik Y, Gélinas C, Needham DM, Slooter AJC, Pandharipande PP, et al. Clinical practice guidelines for the prevention and management of pain, agitation/sedation, delirium, immobility, and sleep disruption in adult patients in the ICU. Crit Care Med. 2018;46:e825-73.

35. Davydow DS, Gifford JM, Desai SV, Needham DM, Bienvenu OJ. Posttraumatic stress disorder in general intensive care unit survivors: a systematic review. GenHospPsychiatry. 2008;30:421-34.

36. Smith GT, McCarthy DM, Anderson KG. On the sins of short-form development. Psychol Assess. 2000;12:102-11.

\section{Publisher's Note}

Springer Nature remains neutral with regard to jurisdictional claims in published maps and institutional affiliations. 